ojs.uv.es/index.php/qfilologia/index

Rebut: ı6.06.2020. Acceptat: 06.09.2020

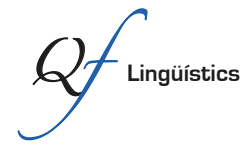

Per a citar aquest article: Herget, Katrin \& Alegre, Teresa. 2020. "A temática da terceira idade - estudo de corpora jornalísticos em alemão e português”. Quaderns de Filologia: Estudis Lingüístics XXV: 43-56.

doi: $10.7203 /$ QF.25.19068

\title{
A temática da terceira idade - estudo de corpora jornalísticos em alemão e português
}

\section{Ageing - A Corpus-Driven Study of Newspaper Texts in German and Portuguese}

\author{
KATRIN HERGET \\ Universidade de Aveiro| CLLC \\ kherget@ua.pt \\ Teresa Alegre \\ Universidade de Aveiro| CLLC \\ teresaalegre@ua.pt
}

Resumo: As designações empregues para referir as pessoas da terceira idade, bem como para descrever o universo que as rodeia, refletem a perceção da sociedade sobre o tema. Essa linguagem suscita uma reflexão crítica sobre fenómenos de tabus linguísticos e de eufemismos, que são particularmente interessantes de analisar quando se estudam e contrastam línguas. A perceção intuitiva da linguagem utilizada na comunicação social carece, no entanto, de instrumentos de análise que nos permitam um conhecimento mais exato das designações empregues e dos seus contextos. Para tal, a análise de corpora é uma metodologia que permite a identificação e descrição mais precisas dos fenómenos linguísticos em análise, tanto em termos quantitativos como qualitativos. O estudo que aqui apresentamos insere-se, portanto, numa perspetiva linguística e contrastiva. A pesquisa centra-se sobre o campo semântico da terceira idade, tendo por base corpora de textos da imprensa escrita alemã e portuguesa. A evolução demográfica e as alterações sociais do último século tornam a análise deste campo particularmente interessante. Tal justifica a existência de diversos estudos sociolinguísticos em várias línguas.

Palavras chave: terceira idade; análise de corpora; textos jornalísticos; campo semântico; alemão-português.

\begin{abstract}
The designations employed for senior citizens, as well as to describe the universe around them, reflect society's perception of these issues. This language gives rise to critical reflection on phenomena of linguistic taboos and euphemisms, which are particularly interesting to analyse when studying and contrasting languages. The intuitive perception of the language used in the media lacks, however, tools of analysis that allow us to have a more accurate knowledge of the designations employed and their contexts. To this end, corpora analysis is a methodology which allows a more precise identification and description of the linguistic phenomena under analysis, both in quantitative and qualitative terms. The study presented here is
\end{abstract}


therefore part of a linguistic and contrastive perspective. The research focuses on the lexical-semantic field of the third age, based on corpora texts from the German and Portuguese written press. Reflecting the demographic evolution and social changes of the last century, this field is particularly interesting and has been the object of sociolinguistic studies in several languages. Keywords: senior citizens; corpora analysis; journalistic texts; semantic field; German-Portuguese.

\section{Enquadramento - A problemática do envelhecimento}

O tema do envelhecimento na sociedade europeia torna-se mais evidente quando observamos as estatísticas europeias da evolução demográfica. A fig. I revela as pirâmides da percentagem de população por faixa etária dos anos de 2002 e 20I7. Os contornos (a traço grosso) delimitam a pirâmide da população em 2002 (à esquerda: sexo masculino, à direita: sexo feminino). As cores indicam a pirâmide da população em 2017 (sexo masculino a azul e sexo feminino a amarelo). A sobreposição das duas pirâmides revela a diminuição que se verificou nas faixas etárias abaixo de 40-44 anos e o aumento percentual nas faixas acima de 45-49 anos de idade. No conjunto, observa-se o desequilíbrio da pirâmide, com uma diminuição da base, isto é, da população mais jovem, e um aumento do topo da pirâmide, ou seja, da população mais idosa.

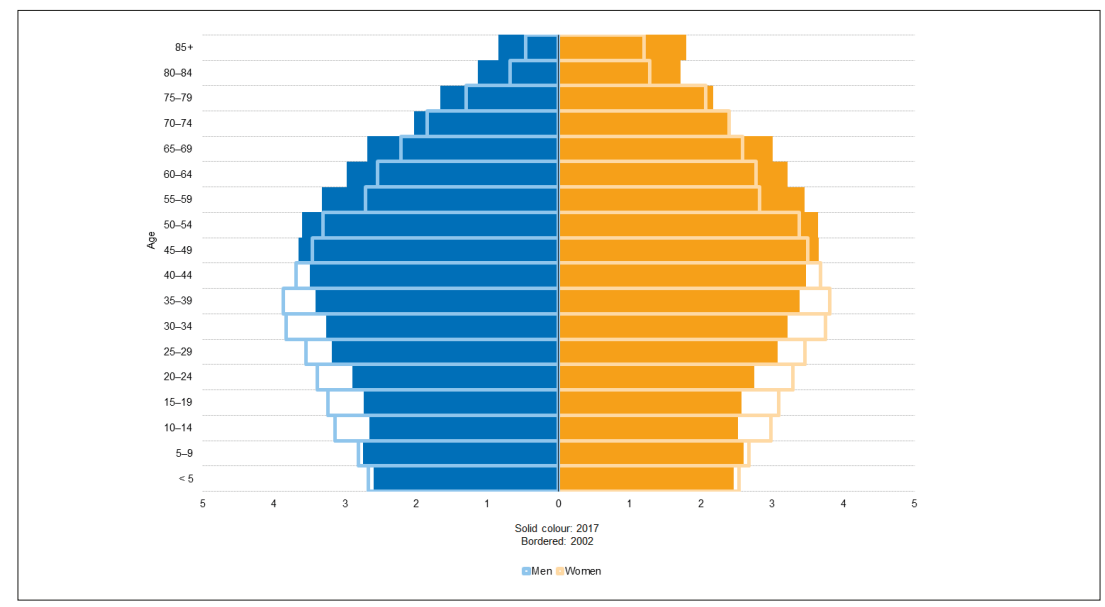

Fig. I. Pirâmides da população europeia 2002-20I7 (Fonte: Eurostat ${ }^{\mathrm{I}}$ )

\footnotetext{
${ }^{\mathrm{I}} \mathrm{https}$ ://ec.europa.eu/eurostat/statistics-explained/index.php?title=File:Bev\%C3\%B6lkerungspyramiden,_EU-28,_2002_und_20I7_(in_\%25_der_Gesamtbev\%C3\%B6lkerung)_FPi8-DE.png
} 


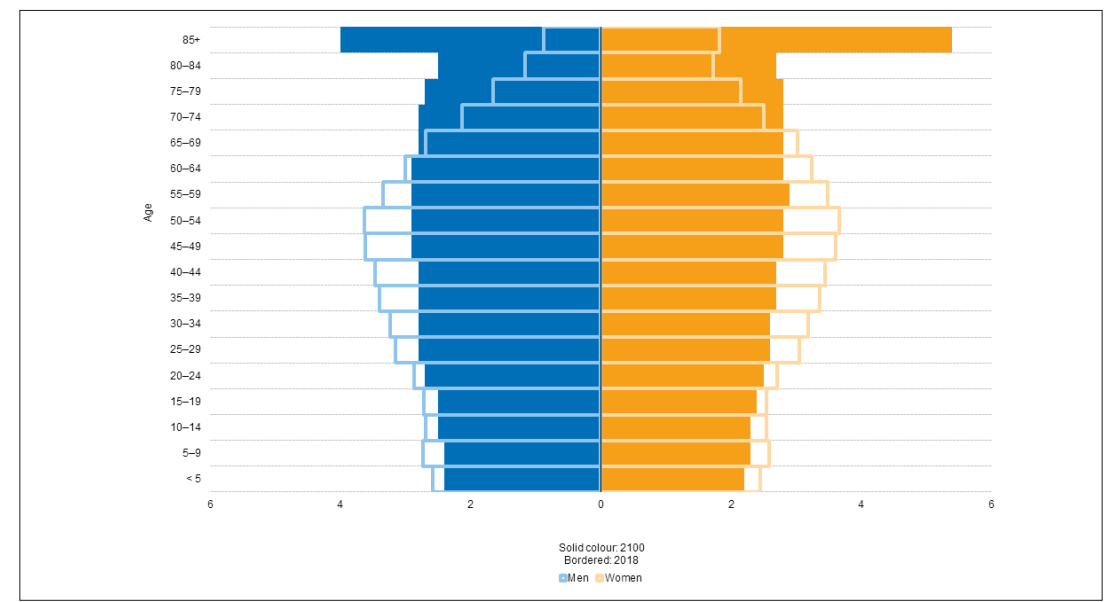

Fig. 2. Pirâmides da população europeia 20I8-2100 (Fonte: Eurostat²)

Na fig. 2 observamos uma projeção demográfica do Eurostat que compara as pirâmides da população europeia em 2018 e 2100. Segundo as previsões do Eurostat a população continuará a envelhecer, pelo aumento da esperança de vida, mas a pirâmide assumirá mais a forma de um bloco, prevendo-se que a população muito idosa aumente consideravelmente.

A problemática social do envelhecimento não é nova. Já em meados do século xx, o psiquiatra americano Robert Butler criara o neologismo age-ism (por analogia com racism e sexism) para designar a discriminação de que, na sua opinião, os idosos americanos eram alvo. Deste conceito americano resultou em português o neologismo idadismo ("atitude preconceituosa e discriminatória com base na idade", segundo o dicionário online Infopédia). De acordo com Butler (1969: 243) age-ism

describes the subjective experience implied in the popular notion of the generation gap. [...] Age-ism reflects a deep seated uneasiness on the part of the young and middle-aged - a personal revulsion to and distaste for growing old, disease, disability; and fear of powerlessness, 'uselessness,' and death.

O conceito de ageism remete portanto para o mal-estar da sociedade em geral e das gerações mais novas, em particular, em relação ao envelhecimento,

${ }^{2}$ https://ec.europa.eu/eurostat/statistics-explained/index.php?title=File:Bev\%C3\%B6lkerungspyramiden,_EU-28,_20I8_und_2100_(in_\%25_der_Gesamtbev\%C3\%B6lkerung).png 
implicando tanto o nível pessoal como o institucional. É um paradoxo que, numa época de avanços médicos e do aumento da longevidade, se constate um receio tão forte de ficar velho, como refere Butler:

In the twentieth century we were offered realistic opportunities for health promotion and disease prevention through public health measures, healthy lifestyles, education, rising wealth, and workplace regulation, in addition to application of new knowledge, such as in understanding hypertension and atherosclerosis. The advent of possible means to delay aging and extend longevity and the growing encouragement of health promotion/disease prevention converge to offer a strategy that could be adapted by individuals and by society in the twenty-first century (Butler, 2008: 13).

Desde o trabalho inicial de Butler, nos anos 6o, muitos outros investigadores se debruçaram sobre esta temática, entre outros, na área da psicologia: Levy \& Macdonald (20I6), sobre a evolução do conceito de ageism, e Ayalon \& Tesch-Römer (20I8), sobre perspetivas contemporâneas do envelhecimento; na área da sociologia médica, Palmore (I999), sobre aspetos positivos e negativos do idadismo. De entre as diferentes disciplinas que estudam este conceito interessa-nos neste estudo a perspetiva linguística, na qual destacamos os seguintes autores: Nuessl (I982) e Fiehler \& Fitzner (2012), sobre a imagem do envelhecimento na linguagem, bem como Palacios (2009), sobre o estudo dos vocábulos velhice e terceira idade no discurso publicitário, no português do Brasil.

A temática do envelhecimento não deixa ninguém indiferente, como se pode ver no exemplo da obra do autor alemão Frank Schirrmacher, intitulada Das Methusalem-Komplott [O Complot de Matusalém, obra não traduzida para português], que teve uma imensa repercussão na sociedade alemã, no início deste século. O jornalista e autor alemão conseguiu agitar a opinião pública ao apresentar os idosos como pessoas discriminadas pela sociedade, fracas, inúteis e carentes de apoio. O autor considerou na altura que a ausência dos idosos na televisão, no cinema e na publicidade ressaltava ainda mais o envelhecimento, não apenas como um processo de decadência, mas ainda mais como uma espécie de doença contagiosa, da qual evitamos aproximar-nos.

Contrariando essa perspetiva pessimista do envelhecimento, verifica-se hoje em dia uma preocupação crescente com a ocupação dos idosos, que se reflete em ações das instituições europeias que fomentam "políticas de envelhecimento ativo" (Förderung des aktiven Alterns), e que se materializam em iniciativas como o "Ano Europeu do Envelhecimento Ativo e da Solidariedade entre Gerações" (20I2), bem como em legislação europeia e nacional, por 
exemplo a "Resolução do Conselho de Ministros n. ${ }^{\circ}$ 76/20I6" (ex. Diário da República, I. ${ }^{a}$ série $-\mathrm{N} .{ }^{\circ} 229-29$ de novembro de 2016 ), que reconhece, em Portugal, o papel "das academias designadas «universidades seniores»" na inserção e participação social das pessoas mais velhas.

$\mathrm{O}$ tema da terceira idade perpassa igualmente a atual sociedade de consumo, marcada pela omnipresença da juventude e pelo sucesso. Neste contexto, o envelhecimento tende muitas vezes a ser camuflado, por exemplo através da aplicação da estratégia de marketing down-aging no design e na comunicação de produto. O conceito de down-aging diz respeito ao alargamento do antiaging, ou seja, o controlo sobre o nosso processo de envelhecimento, associado com a vida ativa em idades avançadas. Isto reflete-se, por exemplo, na apresentação de produtos consumidos fundamentalmente por pessoas da terceira idade como transversais a todas as idades, ignorando, assim, as diferenças de idade que podem discriminar os idosos 3 .

É neste contexto de, por um lado, evitar a imagem do envelhecimento como estigma e, por outro, dar ênfase ao envelhecimento "de qualidade", com a inclusão social dos idosos ativos, que podemos entender a evitação de certos vocábulos e o uso preferencial de outros para designar as pessoas de idade.

\section{Tabus e eufemismos}

O conceito de tabu tem origem na antropologia e está relacionado, em primeira instância, com o sagrado, mas igualmente com comportamentos sociais considerados incorretos. De acordo com Wardhaugh (2006: 239) tabu é definido como

[...] prohibition or avoidance in any society of behavior believed to be harmful to its members in that it would cause them anxiety, embarrassment, or shame. It is an extremely strong politeness constraint. Consequently, so far as language is concerned, certain things are not to be said or certain objects can be referred to only in certain circumstances, for example, only by certain people, or through deliberate circumlocutions, i.e., euphemistically.

A abrangência desta definição serve bem o nosso estudo, uma vez que serve de enquadramento a estratégias de evitação e de substituição através

\footnotetext{
${ }^{3}$ A título de exemplo, veja-se o caso da marca Harley Davidson, que criou uma moto com três rodas (trikes) com a intenção de continuar a apostar em clientes sénior; ou os produtos para a incontinência, cuja publicidade é feita com pessoas de idade com aparência jovem.
} 
de eufemismos que tão importantes são para a nossa análise. Em linguística pragmática, a utilização destas "palavras proibidas" está relacionada com o conceito de face (Goffman, I967), mais concretamente com os atos que a ameaçam e que conduzem à perda da face (Brown \& Levinson, I987).

Neste estudo, não nos ocuparemos dos aspetos sociológicos dos tabus, mas sim das implicações linguísticas (semânticas) do recurso a vocábulos eufemísticos, que a comunicação social usa preferencialmente em determinados contextos da referência à terceira idade.

Uma obra a destacar neste âmbito é o estudo de Schröder (2008) sobre o recurso, na língua alemã, a tabus linguísticos da terceira idade na linguagem do quotidiano. Deste modo, o autor observa que, no contexto de lares de terceira idade, palavras como alt [velho] e Alter [idade] são geralmente evitadas e substituídas por outras. Estas estratégias de evitação conduzem, por um lado, ao uso de eufemismos como Seniorenresidenz [residência sénior], Seniorenheim [lar de seniores] e, por outro, a expressões metafóricas como First-Class-Hotel para designar um lar de terceira idade. Os habitantes dos lares, prossegue Schröder (2008: 7), não são de modo algum velhos, mas antes "seniores" que lá residem e se deixam mimar com tratamentos de Wellness, desporto, cultura e segurança. Num ambiente que lhes é familiar e mantendo a sua esfera privada, sentem-se bem e tomam decisões por si próprios.

\section{Campo semântico da terceira idade}

A diversidade do campo semântico da terceira idade reflete-se em vários estudos sobre o uso das designações preferenciais em diversas línguas. Assim, já nos anos 80, o Conselho Americano National Council on Aging, sob autoria de Louis Harris, conduziu um estudo para determinar as designações socialmente corretas da terceira idade, tendo sido avaliados to termos: senior citizen, retired person, mature American, elderly person, middle-aged person, older American, golden ager, old timer, aged person, and old man/old woman.

Os resultados do estudo apontam para o seguinte: um terço dos inquiridos preferiu a expressão senior citizen, enquanto 55 \% optaram pela designação mature American (Nuessel, I982: 273).

Um outro estudo aprofundado sobre designações da terceira idade em alemão foi realizado por Fiehler \& Fitzner, 20I2, que fazem um levantamento das designações (Tabela I), apresentando-as por ordem de frequência. 


\begin{tabular}{|c|}
\hline Seniorinnen/Senioren [sénior/seniores] \\
\hline ältere Menschen [pessoas mais velhas] \\
\hline Rentnerinnen/Rentner [reformada/o/s] \\
\hline Großeltern [avós] \\
\hline alte Menschen [pessoas velhas] \\
\hline ältere (Mit-)Bürger/ (Mit-)Bürgerinnen [(con)cidadãos /(con)cidadãs mais \\
velhas] \\
\hline ältere Generation [geração mais velha] \\
\hline Pensionärinnen/Pensionäre [pensionista/s] \\
\hline ältere Leute [pessoas mais velhas] \\
\hline Omas/Opas [avozinhas /avozinhos] \\
\hline alte Leute [pessoas velhas] \\
\hline ältere Frauen/Männer [mulheres/homens mais velhos] \\
\hline ältere Damen/Herren [senhoras/senhores mais velhos] \\
\hline Großmütter/Großväter [avós/avôs] \\
\hline Ruheständlerinnen/Ruheständler [aposentada/o/s] \\
\hline Greisinnen/Greise [anciã/s / ancião/s] \\
\hline junge Alte [velho jovem] \\
\hline Grufti(e)s [cota/s]
\end{tabular}

Tabela I. Designações da terceira idade (Fiehler \& Fitzner, 20I2)

A socióloga Felismina Mendes, nos seus "apontamentos sobre o envelhecimento" (Mendes, 20I7) reflete sobre o "significado social da velhice" e sobre as mudanças de nomenclatura, em particular, sobre a evolução das designações de idoso e velho. De acordo com a autora, "velho e idoso, em meados do século passado, designavam condições estruturais de vida diferentes" (Mendes, 20I7: 2I). Enquanto idoso era uma designação "reservada para aqueles que usufruíam de um estatuto social singular resultante de uma situação financeira privilegiada ou de alguma atividade socialmente valorizada", velho era um termo reservado para aqueles que não tinham bens próprios e que, vivendo apenas da força de trabalho, estavam ligados à "indigência e à exclusão" na velhice (Mendes, 20I7: 2I). Na expressão "velhos são os trapos” (subentendendo-se o resto da expressão: "e não as pessoas"), encontramos uma reação a essa conotação negativa do termo velho. 
À semelhança do inglês e do alemão, encontramos no português ${ }^{4}$ um vasto leque de designações recorrentes para o campo semântico da terceira idade, das quais destacamos, a título de exemplo, na linguagem padrão/cuidada: idoso, pessoa mais velha, pessoa de idade, pessoa da terceira idade, reformado, aposentado, pensionista, sénior, ancião, velho jovem, etc. Não entramos, no nosso estudo, em linha de conta com designações coloquiais como avozinho, cota, velhadas, etc.

\section{Metodologia}

Tendo por objetivo o estudo do campo léxico-semântico da terceira idade nas línguas alemã e portuguesa, optamos por uma análise de corpora, de modo a podermos recolher dados mais objetivos sobre os contextos em que as designações ocorrem e as conotações que assumem.

Para tal procedemos inicialmente à seleção dos corpora em ambas as línguas. Sendo o enfoque do nosso estudo a linguagem escrita cuidada, escolhemos corpora já compilados de textos da imprensa alemã e portuguesa.

Para o alemão, a pesquisa das designações da terceira idade baseou-se no corpus DWDS (Digitales Wörterbuch der deutschen Sprache), que é um corpus online de livre acesso, constituído por artigos de jornais alemães (diários e semanários). Para a análise do alemão, foram reunidos, num corpus construído para este efeito, os dados referentes a cada designação da terceira idade, encontrados nos corpora dos três jornais: o semanário Die Zeit (de 1995 até à atualidade), Berliner Zeitung (de I995 até 2005) e Der Tagesspiegel (de I995 até 2005), disponibilizados através da plataforma DWDS.

Para o português, procedeu-se de forma idêntica, procurando corpora online no site da Linguateca 5 . Os corpora utilizados foram o do Jornal Público (CETEMPúblico), com cerca de 209 milhões de palavras (208.424.352) extraídas daquele jornal diário (com extratos de I99I a I998), (https://www. linguateca.pt/ACDC/) e o corpus DiaCLAV, com cerca de 6 milhões e meio de palavras (6.550.993) retiradas de I2.80 artigos das edições online de diversos jornais diários regionais do centro de Portugal, nomeadamente o Diário de Coimbra, Diário de Leiria, Diário de Aveiro e Viseu Diário. De modo a inserir material linguístico mais recente, foram também incluídos extratos de

\footnotetext{
${ }^{4}$ A análise realizada neste estudo incide unicamente sobre o Português Europeu.

${ }^{5}$ https://www.linguateca.pt/
} 
pesquisas online atuais feitas nos sites dos jornais Público e Diário de Notícias. Tal como para o alemão, cada designação portuguesa da terceira idade foi reunida num corpus único, contendo dados dos diversos corpora.

A análise do corpus foi realizada através do programa AntConc, um software de concordâncias, com o qual é possível obter dados estatísticos das ocorrências dos termos e das respetivas colocações.

\section{Análise de corpora}

De modo a podermos comparar a utilização que é feita das designações da terceira idade nas duas línguas, selecionámos para este artigo dois substantivos - Rentner/in [reformado/a] e Senior/in [sénior] - identificados como sendo dos mais frequentes no corpus alemão. A análise da designação Senior, no corpus dos três jornais, com todas as suas possibilidades de criação de compostos, revelou uma grande dispersão de vocábulos (732). No corpus português, foram selecionados os substantivos equivalentes reformado/a e sénior, de modo a estabelecer uma comparação.

\subsection{Corpus alemão}

Na língua alemã, até aos anos 8o, a designação Senior era pouco usual e exclusivamente utilizada como estrangeirismo. Só a partir do final do século xx é que se começou a utilizar esta designação com mais frequência em diferentes domínios da linguagem. Atualmente, os compostos com Senior são tão diversificados que conseguimos extrair quase 600 compostos. Esta criatividade lexical contrasta sobretudo quando comparada com as entradas do dicionário de referência Duden, que contém uma escassa vintena de entradas de compostos, entre as quais podemos encontrar nomes como: Seniorenausweis, Seniorenalter, Seniorenberatung, Seniorengymnastik, Seniorenklasse, Seniorenklub, Seniorennachmittag, Seniorenpass, Seniorenreise, Seniorenresidenz, Seniorensport, Seniorentelefon, Seniorenteller, Seniorenstudium, Seniorentreff, Seniorenwohnheim, Seniorexperte; e o adjetivo seniorengerecht [adequado aos seniores]. É, no entanto, preciso ter em conta que, ao contrário dos exemplos encontrados nos jornais, os compostos do dicionário constituem unidades lexicais estáveis.

Um bom exemplo para ilustrar a evolução semântica das designações da terceira idade é o uso preferencial (na atualidade) do vocábulo Seniorenheim [lar de seniores], em detrimento de Altersheim [lar de idosos]. Ao longo dos 
tempos, a palavra Senior foi perdendo a conotação negativa presente na origem latina de senex (lat. senere - ser velho, fraco; senescere - envelhecer, desvanecer-se; lat. senilis - senil), passando a estar associada a uma imagem positiva do processo de envelhecimento.

Após a seleção dos substantivos Senior e Rentner, importava analisar no corpus os adjetivos mais frequentes a estes associados. Para obter uma listagem sistemática, foi utilizada a ferramenta TagAnt, que permite a criação de um corpus anotado com a possibilidade de filtrar os adjetivos. Desta forma, foi possível obter uma listagem dos adjetivos qualificativos associados a cada substantivo, que, na língua alemã, se situam à esquerda do nome (Fig. 3).

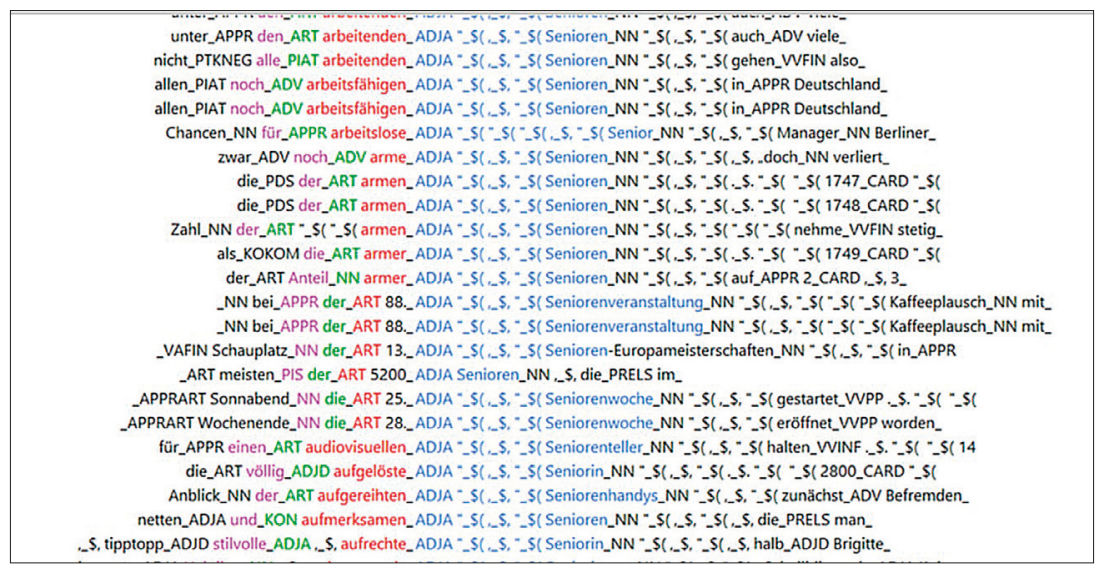

Fig. 3. Análise de TagAnt referente à ocorrência de adjetivos relacionados com Senior**

A análise dos adjetivos qualificativos associados a Senior*, acompanhados da respetiva frequência (fig. 3), revelou um campo semântico bem mais positivo que a análise de ADJ+Rentner*. Enquanto, por exemplo, Rentner [reformado] surge frequentemente associado ao adjetivo de conotação negativa arm [pobre] (66), com o vocábulo Senior isso não sucede. No fundo, os adjetivos associados a Senior (aktiv [ativo], agil [ágil], rüstig [vigoroso], reiselustig [que gosta de viajar], sportlich [desportivo]) são mais positivos do que os associados a Rentner e remetem para uma imagem diferente da terceira idade, que contrasta com a ideia tradicional do envelhecimento. As pessoas mais velhas participam ativamente na vida social e veem a velhice como uma nova etapa da vida, com novas possibilidades e desafios.

Os avanços na medicina contribuíram para o aumento da esperança de vida e criaram um novo grupo social com uma nova identidade que já não se 
revê na designação de Rentner [reformado]. A análise do cotexto de Rentner e a subsequente extração dos substantivos revela uma predominância de temas relacionados com a assistência financeira e de saúde aos reformados, tal como podemos verificar na seguinte extração:

- Altersbezüge [pensões]

- Beitragszahler [contribuinte]

- Geringverdiener [trabalhadores com remunerações baixas]

- Grundsicherung [rendimento básico]

- Krankenversicherung [seguro de doença]

- Nullrunde [congelamento de salários]

- Pflegeversicherung [seguro de prestação de assistência]

- Regierung [governo]

- Rentenreform [reforma das pensões]

A análise dos adjetivos atributivos associados a Rentner revelou-se particularmente interessante, dando lugar às seguintes ocorrências: alt [velho] (82), arm [pobre] (66), rüstig [vigoroso] (75), wohlhabend [abastado] (I9), bedürftig [necessitado] (I5). Os adjetivos mais frequentes trazem uma conotação negativa a Rentner. Adjetivos como armutsbedroht [ameaçado pela pobreza] e armutsgefährdet [em risco de cair na pobreza] também se encontram no corpus, mas são menos representativos (respetivamente, 6 e 3 ocorrências).

\subsection{Corpus português}

No corpus português foram igualmente analisados os vocábulos sénior e reformado, para se poder estabelecer uma comparação com os resultados da língua alemã.

Relativamente a sénior* verifica-se, em primeiro lugar, que este, ao contrário do alemão, é usado principalmente como adjetivo, embora possa também ser utilizado como substantivo. De facto, a sua utilização não é tão recente na língua portuguesa como na língua alemã. O adjetivo sénior tem o significado de "mais velho", "profissional experiente" e surge frequentemente associado ao contexto empresarial ("aquele que é mais antigo e graduado em determinada profissão ou atividade ou que ingressou há mais tempo no ramo profissional ou em uma empresa", segundo a definição presente no dicionário Houaiss) e ao contexto desportivo "maior de I8 anos" por oposição a júnior (desportista que passou a idade de júnior mas que ainda não é veterano). 
No português, a associação mais comum do termo sénior é o desporto. Neste contexto existem as categorias de júnior, sénior e veterano, o que contrasta com a designação Seniorenmannschaft [equipa sénior], na língua alemã, que não designa uma equipa de maiores de i 8 anos mas sim uma equipa de veteranos. Convém, no entanto, salientar que em contextos institucionais de terceira idade a palavra sénior também designa uma pessoa de idade. A associação de sénior* com o desporto reflete-se na frequência das colocações com equipa (194), futebol (84), plantel (47), masculin* (27), presidente (II), feminin* (19), basquetebol (10), andebol (8), equipa (6), torneio (5), corrida (4), campeonato (3), atleta (3), treinador* (4).

Não obstante, o cotexto de sénior remete para designações de atividades profissionais: graduado (7) (neste caso concreto, associado a assistentes médicos), analista (5), consultor (4), presidente (3) economista (3), na área da economia; diplomata (4), cientista (3).

O vocábulo sénior remete também para o campo semântico da terceira idade, em colocações com universidade* (36), turismo (2I).

À semelhança do que constatámos para a língua alemã, também em português verificamos uma evolução semântica nas designações dos lares para a terceira idade, às quais se vêm acrescentar expressões como residência sénior ou residencial sénior. No entanto, a designação lar de idosos permanece igualmente usual.

Ao contrário do alemão, não registámos coocorrências de sénior* com adjetivos como ágil ou vigoroso, tendo surgido unicamente uma ocorrência de sénior ativo ${ }^{6}$.

$\mathrm{Na}$ análise de reformad* (Fig. 4) destacam-se a coocorrência com pensionista (75) e com o advérbio compulsivamente (30). Registam-se ainda as seguintes coocorrências: professores (I9), desempregados (I9), militares (I8), coronel (I8), portugueses (I7), idosos (I7). Através da análise dos exemplos encontrados, podemos concluir que o vocábulo identifica, antes de mais, o estatuto social dos que já não exercem atividade profissional, sendo a díade reformados e pensionistas muito comum. Além disso, na associação com desempregados ou com o advérbio compulsivamente, apresenta uma conotação negativa.

\footnotetext{
${ }^{6}$ Embora ultrapassando o nosso campo de estudo, uma pesquisa simples em páginas institucionais das autarquias portuguesas revela muitos exemplos de sénior ativo, o que nos leva a constatar as limitações do estudo.
} 


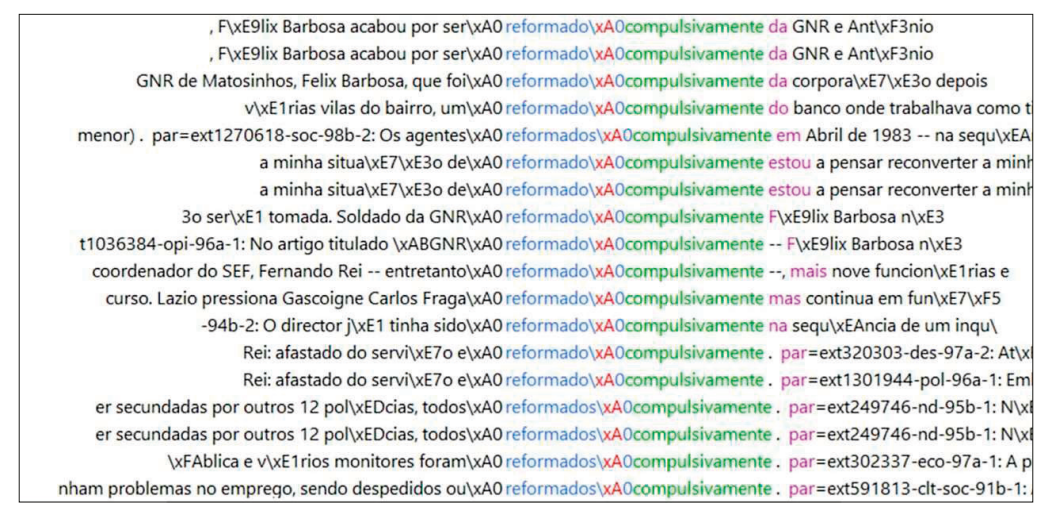

Fig. 4. Análise de reformad*

\section{Conclusão}

O objetivo deste estudo foi a análise das designações Senior / sénior e Rentner / reformado em alemão e português. Observámos que na língua alemã o substantivo Senior é mais utilizado no contexto da vida cultural, da vida ativa e do lazer, mas também no contexto da habitação para a terceira idade e, genericamente, no contexto institucional. Verificámos que, normalmente, este nome apresenta uma conotação mais positiva que o substantivo Rentner, que é frequentemente empregado em temas socioeconómicos. Os adjetivos qualificativos em coocorrência com Senior, como rüstig, aktiv e agil, refletem uma imagem da idade mais positiva, apresentando caraterísticas que remetem para uma pessoa pró-ativa e dinâmica.

Relativamente ao português, constatámos uma tendência semelhante à da língua alemã no emprego cada vez mais comum do vocábulo sénior em contexto institucional, para designar positivamente a faixa social e etária que está em crescimento na sociedade europeia. Este facto não será certamente de estranhar numa Europa que procura promover políticas sociais alargadas aos diversos Estados europeus e que publica estudos e legislação que é vertida para as diferentes línguas e difundida no espaço europeu. Contudo, o corpus português revelou a associação preferencial deste substantivo ao universo desportivo. Já o termo reformado/a evidencia uma maior proximidade ao equivalente alemão Rentner, pelo facto de se encontrar associado a contextos sociais, contudo, o corpus não revela associação com adjetivos de cariz negativo.

Este estudo preliminar revelou a necessidade de proceder à análise de outras designações deste campo semântico através do recurso à ferramenta de 
extração de concordância, o AntConc. Consideramos que estudos desta natureza nos permitem conhecer melhor os recursos lexicais de ambas as línguas e identificar semelhanças e diferenças nos seus usos. Além disso, fez-nos tomar consciência da discrepância de recursos terminológicos em ambas as línguas. Enquanto para a língua alemã acedemos facilmente a corpora de textos jornalísticos atuais, para o português europeu a disponibilidade é muito limitada e pouco atual. Este facto levanta certamente novos desafios a investigação em língua portuguesa.

\section{Bibliografia}

Ayalon, Liat \& Tesch-Römer, Clemens (eds.). 20I8. Contemporary Perspectives on Ageism. Springer Open

Brown, Penelope \& Levinson, Stephen. 1987. Politeness: some universals in language usage. Studies in interactional sociolinguistics. Cambridge: Cambridge Univ. Press

Butler, Robert Neil. 1969. Ageism: Another form of bigotry. The Gerontologist 9(4): $243-245$.

Butler, Robert Neil. 2008. The Longevity Revolution. The Benefits and Challenges of Living a long Life. New York: Public Affairs.

Fiehler, Reinhard \& Fitzner, Wolfgang. 20I2. Bilder des Alters im Sprachgebrauch. Em Berner, Frank; Rossow, Judith \& Schwitzer, Klaus-Peter (eds.) Individuelle und kulturelle Altersbilder. Expertisen zum Sechsten Altenbericht der Bundesregierung. Band 1. Wiesbaden: Verlag für Sozialwissenschaften, 289-372.

Goffman, Erving. I967. Interaction ritual. Chicago: Aldine Publishing Company.

Levy, Sheri R. \& Macdonald, Jamie L. 20I6. Progress on Understanding Ageism. Journal of Social Issues 72(I): 5-25. doi: IO.IIII/josi.I2I53

Mendes, Felismina Rosa Parreira. 20I7. Alguns apontamentos sobre o envelhecimento. Em Lage, Isabel (coord.) Cuidados e Envelhecimento Perspetivas da Enfermagem. Vialonga: Coisas de Ler, I7-30.

Nuessel, Frank. I982. The Language of Ageism. The Gerontologist 23(3): 273-27.

Palacios, Annamaria da Rocha Jatobá. 2006. Velhice, palavra quase proibida; terceira idade, expressão quase hegemônica: apontamentos sobre o conceito de mudança discursiva na publicidade contemporânea. XX Encontro da Associação Portuguesa de Linguística (APL). Lisboa: Universidade de Lisboa, I3-I5 de outubro.

Palmore, Erdman. 1999. Ageism: Negative and positive ( $2^{\mathrm{a}}$ ed.). New York: Springer Publishing Company.

Schröder, Hartmut. I995. Tabuforschung als Aufgabe interkultureller Germanistik. Jahrbuch Deutsch als Fremdsprache 21: 15-35.

Wardhaugh. Ronald. 2006. An Introduction to Sociolinguistics (5 ${ }^{\mathrm{a}}$ ed.). Malden: Blackwell. 